\title{
Application of RFID Technology in Logistics
}

\section{Management}

\author{
Zhang Xiaolei \\ School of Economic and Management \\ Shengyang Aerospace University \\ Shengyang China \\ 32682661@qq.com
}

\begin{abstract}
As a new automatic recognization technology, RFID technology was born in 1990s. With the continuous development and matures of it, it was implied in many aspects. Especially in logistics, it was implied very widely and deeply.Firstly, at the beginning of it is the RFID technology and how it works, the article introduces the composition of RFID, advantages of RFID system, working principle and made a simple comparison with other automatic identification technology. Then it focuses on the applications of RFID technology in some major aspects in logistics management. Subsequently it explained the advantages of RFID technology in logistics management, and its obstacles and the prospects of development in logistics management. Finally, it introduces and analysises the application of RFID technology in a clothing distribution center. A brief introduction on application of RFID technology to the distribution center was mad.
\end{abstract}

Keywords- Radio Frequency Identification Technology; Logistics Management; The Study of Application

\section{INTRODUCTION}

As a kind of important automatic identification technology in this century, RFID becomes the hot point of research and application in the world and the application prospect of this lies in many fields. It has many advantages in the aspects including lowering operation cost, improving logistics and supply chain management level and enhancing competitiveness of enterprises.

As a kind of non-contact automatic identification technique, the technology is a kind of automatic identification technology using sensing radio waves or micro waves to make non-contact two-way communication with purpose of identification and data exchange. Most of RFID application in the retail sector still stays at the research stage. Only a minority of retail companies can realize the RFID system. RFID technology is more efficient than the bar code technology, and it has many features including large label-information storage, automatic identification and anti-counterfeiting performance.

\section{BASIC CONCEPT OF RFID TECHNOLOGY}

RFID is Radio Frequency Identification. The RFID system is usually composed of a reader, transponder, computer network and information processing system. The transponder in the magnetic field of the reader is activated and sends a message. Then reading this information by the reader is the basic principle of system work. The transponder has many features such as non-carrying of batteries, non-contact identification, none-minding dirty and the chip code is special, high security, and long life.

\section{RESEARCH STATUS AT HOME AND ABROAD}

\section{A. RFID Research Status in Foreign Countries}

In the industry, America invests a lot of capital into chip development in RFID field. The scanners that can read the RFID and bar code at once are developed by many companies such as Symbol.

In other countries including Europe and the United States, Frankfort International Airport in Germany used RFID technology to make asset management and obtained great success and improved production efficiency and accuracy.

\section{B. Domestic Research Status of RFID}

Now, in a lot of areas in China, RFID technology has been widely used and has achieved remarkable results.

In circulation of commodities, China Tobacco Administration made research on EPC RFID application in tobacco industry to make relevant departments to have effective control of cigarette logistics.

In product anti-counterfeiting, application plan of "RFID special goods anti-fake tracking system" is developed and launched, and is successfully applied in military material.

In transportation, the "one card all way" project can be used for bus taking and this greatly improved ticket selling efficiency.

In storage, electronic label has many features including none-relationship between reading \& writing and direction, short distance reading and taking, at-once many-articles reading. This greatly improves the efficiency of warehousing product information collection.

\section{APPLICATION OF RFID TECHNOLOGY IN LOGISTICS MANAGEMENT}

\section{A. Purchase Sections}

In the section of purchase, the internet makes an enterprise enable to achieve quick reaction purchase and timely purchase, to make real-time command of sales and 
supply status in the whole supply chain, to understand inventory information, supply and demand information and so on in a better way, to timely make adjustment or to establish purchase plans and to make efficient purchase orders.

An enterprise can integrate information resources through the internet, informationize purchase, realize automation of purchasing management, improve the speed of information transmission (namely to put purchase as the source and to precisely track sections of purchase orders) and to choose the optimal selection of purchase after comparison. At the same time, the enterprise can timely query and understand the plans, orders, delivery, etc in the whole purchase course in order to monitor, adjust and manage activities on them and to use unified method of optimized purchase. This can also reduce the cost in the procurement process and improve operation efficiency.

\section{B. Storage Sections}

In the storage section, the application of RFID technology greatly improves the degree of informationization of the storing section. The warehousing management system based on RFID technology (as shown in FIG.1: Main Business Process of the System) has outstanding advantages in performance and functions. When RFID technology is applied in the warehousing management system, operation cost can be quickly reduced and the business cycle can be shortened.

RFID warehousing management system has the following advantages,

1) Improving the accuracy of goods information and status query,

2) Helping enterprises reduce cost of inventory management;

3) Making inventory work quicker and more accurate,

The system's sending out alarm as the stock quantity smaller than amount of safety stock,

4) The system's sending out alarm as the stock quantity smaller than amount of safety stock,

5) And timely and accurate inventory information can make management and decision-making more reasonable and accurate.

When applying RFID on warehouses, the working process can be optimized and the finished-product inventory can be reduced. Therefore, this can improve many items including productivity, accuracy and profitability and can improve the level of customer service.

\section{Distribution Section}

1) The specific application of RFID technology in the supply and distribution center (the specific flow diagram is shown in FIG.2: Diagram on Optimization of RFID Distribution)

\section{a) Stock In and Inspection}

When labeled goods are in the distribution center, the cargo information will be written at the inlet of the reader for automatic recognition and reading. The system will automatically update the inventory list according to the information received.

\section{b) Trimming and supplementary goods}

When goods need to be trimmed, the sorting carrying carts with the mobile readers would make sorting and trimming of goods. The carts would automatically deliver goods to the accurate locations according to the indication of the distribution center. Meanwhile, the inventory sheet would be updated and the new locations would be recorded.

\section{c) Filling of Order Form}

The inventory and management center is closely linked with each other through the RFID system to complete order filling of the management center, and to put the operation of sending, stock-out, inspection and inventory updating as a work flow.

\section{d) Transport of Goods Stock Out}

The transportation of goods will realize high-degree of automation after application of RFID technology.

2) Benefits to distribution with application of RFID technology

Application of RFID technology at the distribution center, the benefits are mainly embodied in the following aspects,

\section{a) Saving manpower cost}

When application of the RFID technology is made, almost all scanning and checking are automatically carried out.

\section{b) Goods First-Entry and First-Out Management}

In the application of the RFID and other advanced technology, Information including storage time and location information on each batch of incoming goods will be automatically recorded and saved.

\section{c) Improving inventory list accuracy}

The system can automatically scan and record each cargo storage location, and due to timely updating and recording of the system, inventory information is accurately recorded.

d) Optimizing business processes and improving work efficiency

The distribution management is made after application of RFID Technology, which improves and optimizes the distribution center of the business process to a great extent.

\section{e) Improving efficiency of order filling}

Due to application of RFID technology, the reliability of goods in many aspects including storage, sorting and complementary are improved, and the business is timely made, Therefore, many mistakes or unreasonable orders are avoided in the course of order filling.

\section{f) And consumption of goods}

Loss of goods often occurs in the process of transportation, which is difficult to avoid for the distribution center. Because the management by RFID technology is about each article, the loss rate of goods can be reduced.

\section{Transportation Section}

In the transportation process, combination of RFID technology and GPS makes that the logistics and transport process can be fully and visually tracked. The information identification system makes transport tools directly pass, which saves customs clearance time. What is more, RFID reading system installed on the transport routes can make real-time vehicle tracking, and timely understand track 
information of the goods. On the remote dispatch management, this improves safety of goods and this has great importance.

\section{ADVANTAGES WITH APPLICATION OF RFID TECHNOLOGY IN LOGISTICS MANAGEMENT}

As high information technology, RFID technology fully demonstrates its great value with its many features including rapidness, real-time feature and accurateness. Its advantages are very obvious, which mainly have the following points:

\section{A. Shortening of Operation Flow}

Because many features including automatic identification of RFID technology, in some business activities in logistics management, stock-in and stock-out work needs a lot of manual operation, which makes the process more complicated. However, with application of RFID technology, the operation will be automatically identified and processed by the RFID system for Real realization of the process automation. In this way, this greatly reduces time for the complex course, and shortens the operation process and improves the operational efficiency.

\section{B. Transmission of Information is more Quickly and \\ Accurately, and Improve Quality of Stock-Taking}

In the stock-taking, because each box and plate for the RFID system are stuck with RFID tags, with handheld RFID reader can automatically get all the information on labels through all the shelves, and make stock taking with PC machines in the network range. The omission and errors in traditional stock-taking operations are reduced.

\section{Increasing of Throughput Quantity of Distribution Centers}

When distribution center's operation efficiency (the main operation) is improved, the processing ability of the distribution center on goods will greatly increase, which can increase the daily throughput quantity of the goods distribution center and obtain more economic benefits for the distribution center.

\section{Reduction of Operating Costs}

Because of all the outstanding characteristics of RFID technology, the system can efficiently process operation which requires a lot of manpower and the accuracy of the RFID system in business processing is much higher than that with manual operation. Therefore, this not only solves the investment problem of high cost and solves the problem of low efficiency.

\section{E. Logistics Tracking}

Because each RFID electronic tag has a unique electronic product code, tracking and positioning of a tagged article or vehicle equipment can be realized with computers, network, database technology, etc.

\section{APPLICATION OF RFID TECHNOLOGY IN Z COMPANY'S DISTRIBUTION CENTER}

Taking a brand clothing company $\mathrm{Z}$ as an example, the effect with application of RFID technology at the distribution center is analyzed. The $\mathrm{Z}$ Company's economic strength is very strong, and it has a number of stores and a distribution center in B city. To provide warehousing and distribution service for all the clothing stores to is the main work of the logistics center. Z Company is a large-scale clothing enterprise, and it makes seasonal production. It distributes all kinds of clothing and other clothing toward the sales stores, and it needs a logistics system which can handle large amounts of information and adapt to changes on the market in order to exactly know various dress warehousing and distribution information of clothing divided according to seasons. The afterward coordinating of all sections makes coordinated operation of the system.

\section{A. Characteristics of Clothing Distribution Center Operation}

1) Clothing Distribution Center Needs to Achieve Rapid Response

The clothing market demands change, which will make prediction of market demand difficult and make rejection business very complex due to features of clothe samples. Seasonal and fashion cycles are the obvious feature of clothing. The short supply situation often occurs in new product sales. However, after a period of time, the new style attracts people's attention. Therefore, to ensure the timely supply of new goods in the commodity sales is very important so as to quickly response to market demand.

2) Clothing Distribution Center Taking Single Product Management as Major Work

The types, styles, colors and sizes of clothes are different and the management becomes very complex, so the thought of single-product management is particularly important for clothing management. Detail goods management in the supply chain of clothing enterprises is an important principle of single-product management.

3) Much Circulated Processing in Clothing Distribution Center

Because the clothing distribution center has many items of processing operation, for example, ironing, processing of fabric subject to wrinkles, sorting and packing such as sorting and packaging according to customers' requirements, quality inspection, such as sorting according to color differences and then to make packing; and plate sticking such as hanging clothing plates printing barcode labels, etc.

\section{SPECIFIC APPLICATION ANALYSIS}

Now, according to the existing problems of $\mathrm{Z}$ clothing company and the operation characteristics problem and distribution center, the application of RFID technology at the $\mathrm{Z}$ company's distribution center is mainly analyzed. In this article, only about sections including the planning in the RFID technology implementation steps are briefly discussed.

\section{A. Analysis of Distribution Center Management}

With application of RFID technology at the distribution center of Z Company, the complete logistics business process is realized. The detailed business process is as follows, when the clothes labeled reaches the distribution center, a reader at door collects related clothes data, and only those consistent with the electronic purchase sheets can be accepted. At completion of acceptance work, the 
sorting vehicles with readers will automatically sort the clothing. At this time, simple processing on some clothing is made and the basic processing is about hanging price cards, matching clothes, etc. Then the stock-out orders should be waited for. When the store sends an electronic order to the distribution center and the order is received, stock-out work should be made. When the electronic order is received, the reader would mark the location of checked articles, the operating personnel would take a reader to sorting and to obtain the required items. Simple packaging of clothing before delivery is made to meet the transportation. When the store receives the goods, it should make confirmation toward the distribution center and then the distribution center will update data and timely adjust inventory status. The specific process is shown in FIG.3 Clothing Company Z's Management Procedure.

\section{B. Chart of Internal Business Flow at Distribution Center}

The chart of internal business at the clothing company Z's distribution center with application of RFID Technology is shown in FIG.4. Internal Process of Distribution Center (This article only discusses the internal procedure of the clothing company Z's distribution center after application of RFID technology).

\section{CONCLUSION}

The RFID technology not only promotes development of the electronic information industry, but also promotes development of all industries in economy. RFID technology can be applied not only to the production process but also many areas such as logistics management and transportation. This will become the most commonly used automatic identification technology in the twenty-first Century.

Through profiling and introduction of the theory and features of RFID and introduction of many sections such as purchase, transportation, warehousing, packaging, handling and distribution of RFID in the logistics industry, application of RFID mode with cases in the logistics industry is discussed and analyzed.

Application of RFID technology in logistics management is still at the beginning stage of growth, and it still has many shortcomings. With its effect on logistics management, RFID technology will obtain strong development.

\section{REFERENCE}

[1] Ning Huansheng, RFID Key Projects and National Network [M], Beijing: Mechanical Industry Press, 2010.190-191

[2] Zhang Youguang, Du Wan, Zhang Xiuchun and Yang Ziqiang. Comparison and Analysis of Three largest RFID Standard Systems in the World [J]. China standardization, 2006,(03):29-32.

[3] Gunn Xuefei. Application of RFID technology in Supply Chain Management [J]. Logistics Technology, 2010, 10 (28), 110-119

[4]Anon Source.RFID brings advantages of speed and information[J].EI Paekaging Magazine,2005,8(2):17-19.

[5]Fairley,Mike.RFID smart labels-A challenge for converters[J].AP Australian Printer

Magazine,2005,(4):48-51.

[6] Guan Liping, Study on Logistics Information System Framework [D]. Beijing: Beijing Jiaotong University, 2005

[7] Huang Yong, Zeng Wei and Zhang Haibin, Study on Application of Information Technology in Enterprise Supply Chain Management [J]. China Management Information (Comprehensive Edition), 2007, (05): 27 


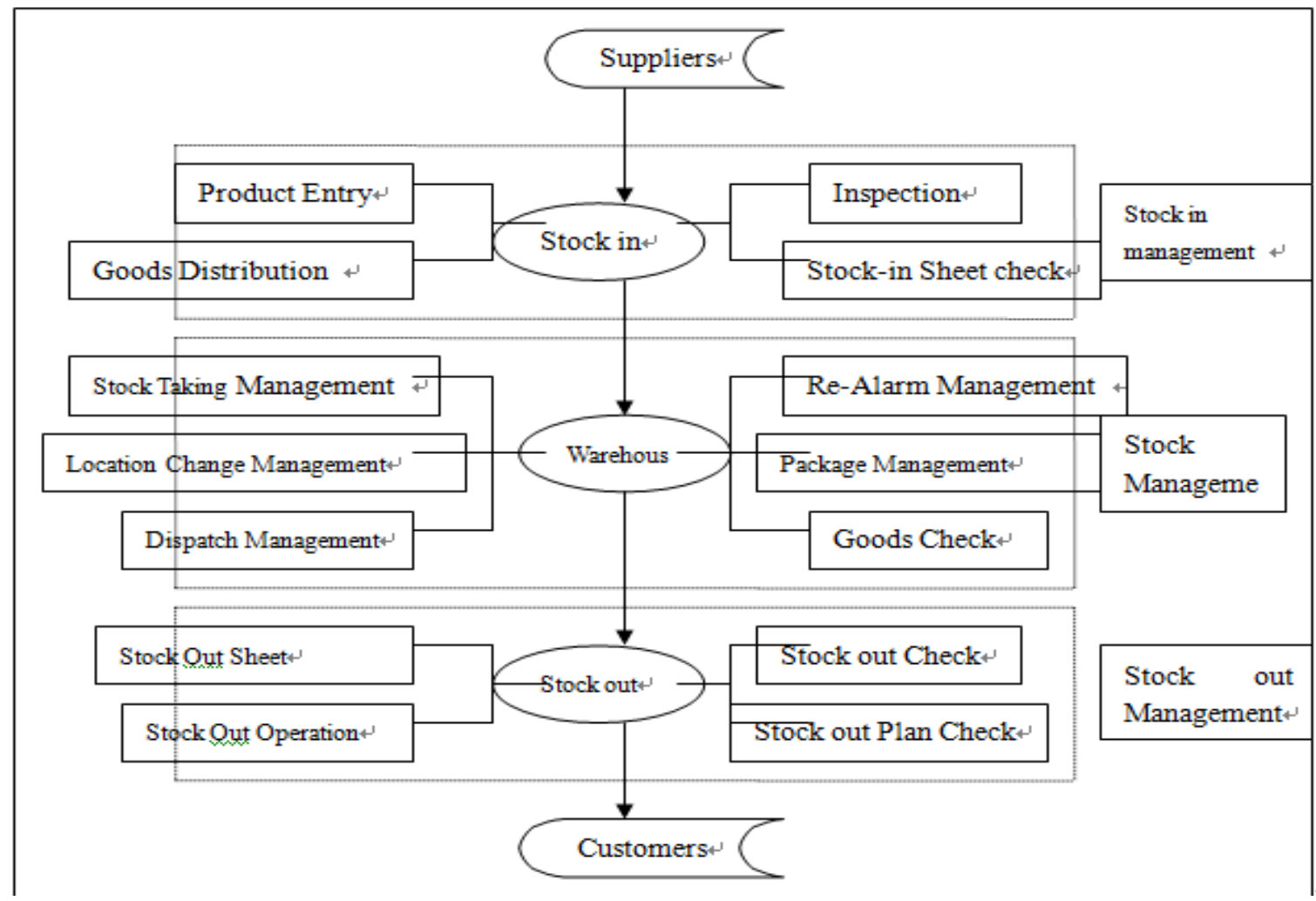

Figure 1. Main Flow of the Sytem

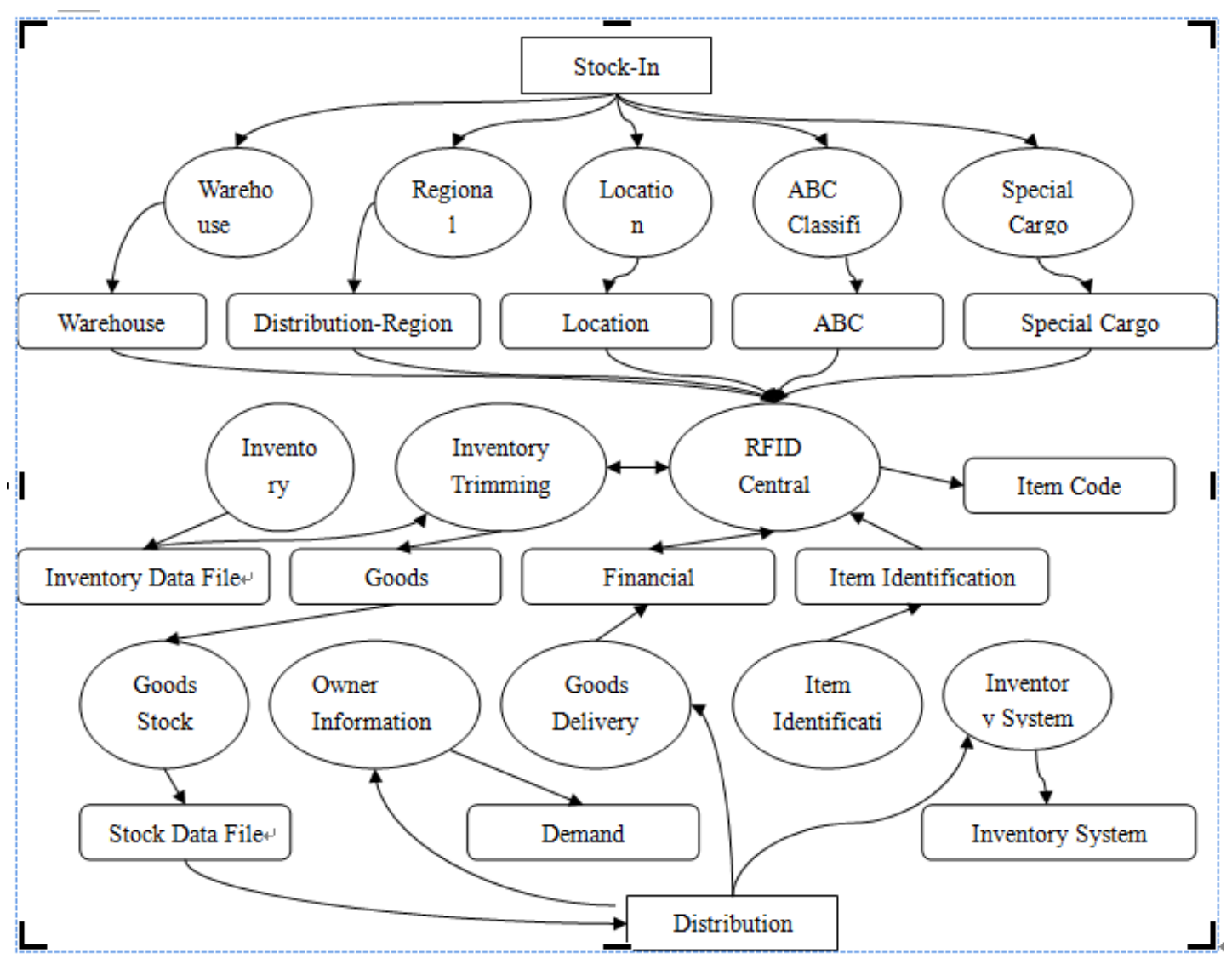

Figure 2. Diagram on Optimization of RFID Distribution 


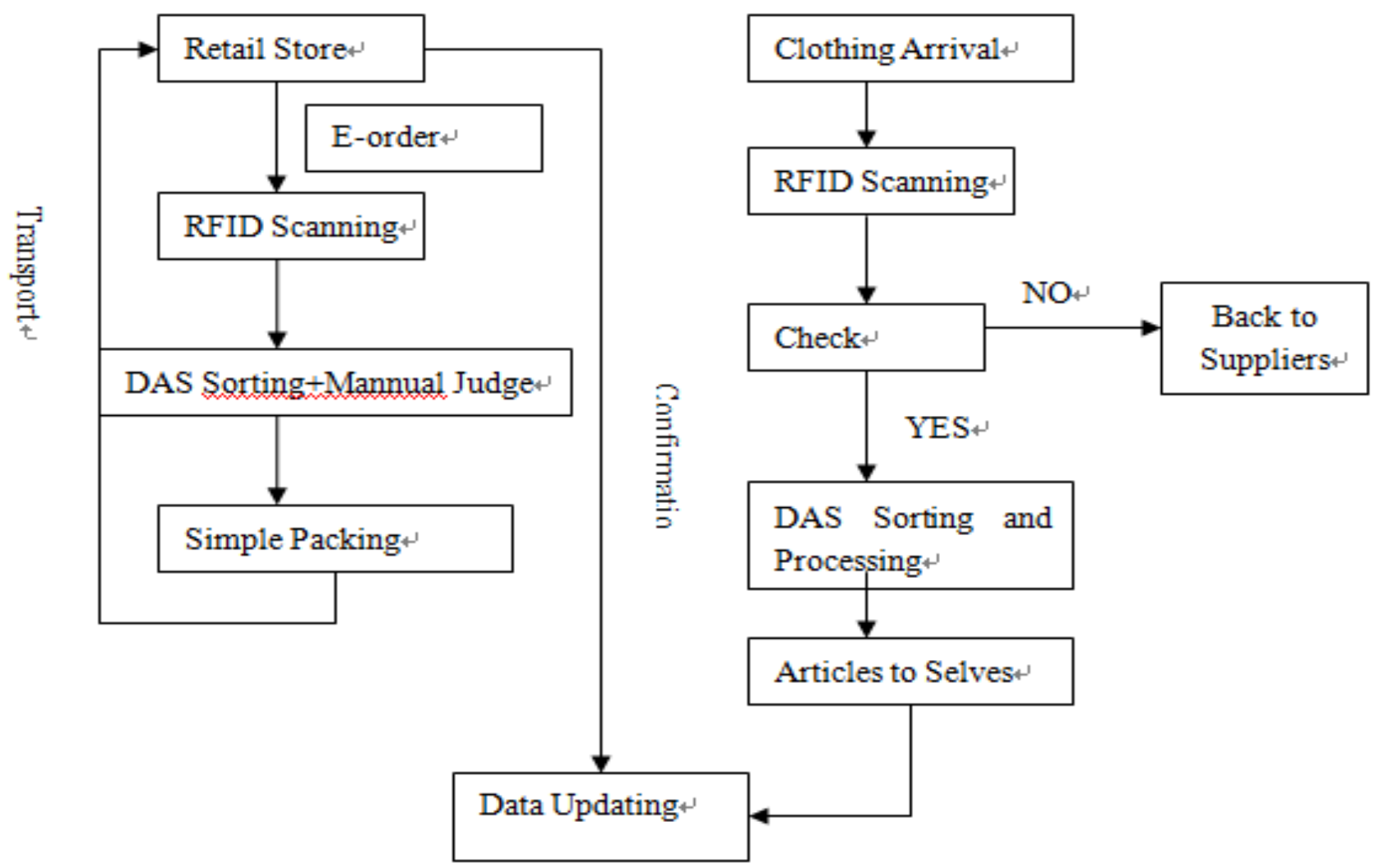

Figure 3. Clothing Company Z's Distribution Center Management F 


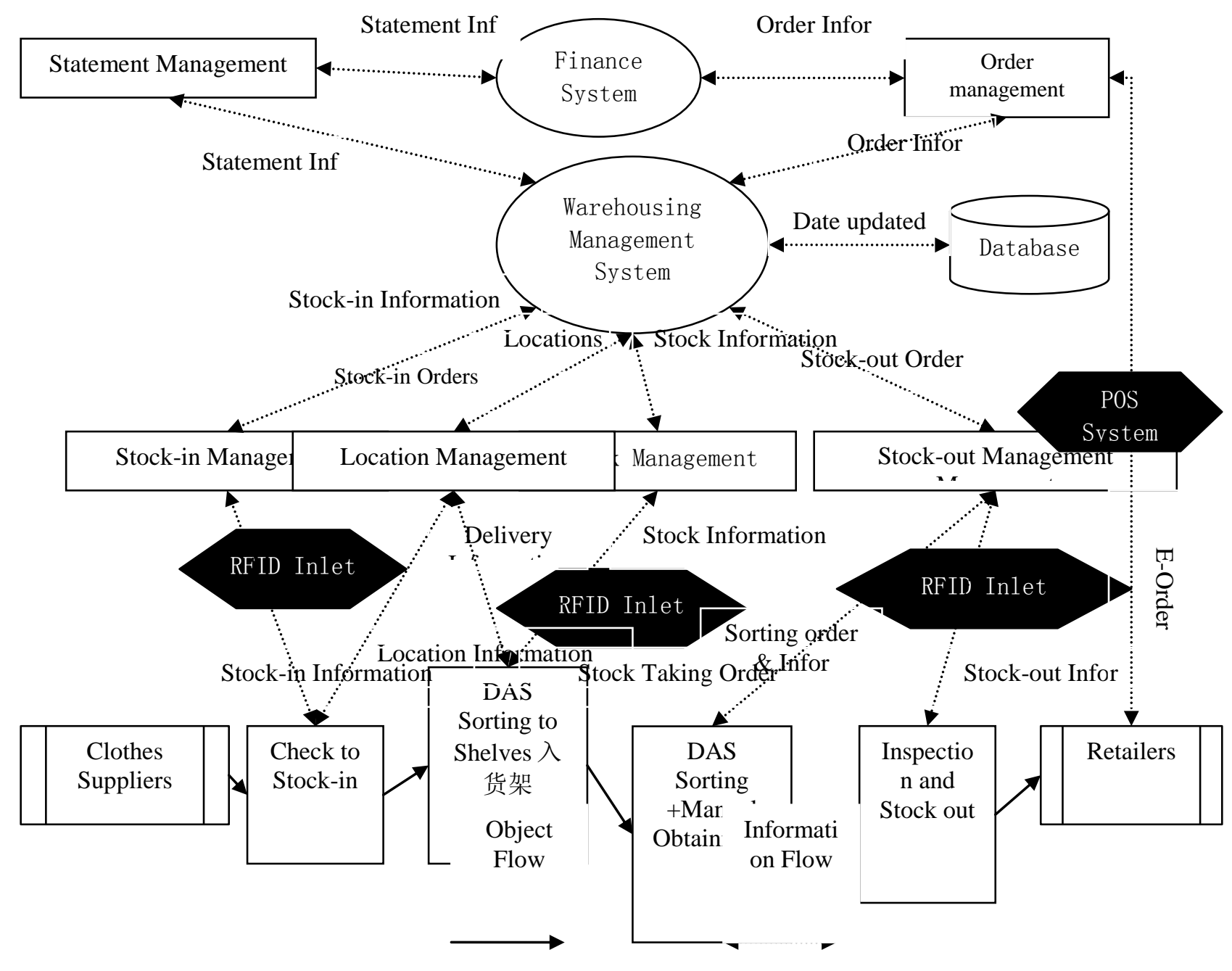

Figure 4. Internal Process of Distribution Center 